\title{
Camp or College?
}

Student Perspectives from College Computer Science Departments \& Coding Boot Camps on Skills Learned

\author{
Quinn Burke \\ Digital Promise \\ San Mateo, CA, USA \\ qburke@digitalpromise.org
}

\author{
Cinamon Sunrise Bailey \\ College of Charleston \\ Charleston, SC, USA \\ cinamonsunrise@yahoo.com
}

\begin{abstract}
The purpose of this paper is to investigate student perspectives of how college computer science (CS) programs compare to those of coding bootcamps. In particular, the research examines to what degree students report their respective programs instill the necessary interpersonal and intrapersonal skills (i.e., teamwork and resilience) necessary for workforce entry. Prior research from the authors suggests there is a perception among the software industry that college graduates often lack the necessary so-called "soft" skills for successful workforce entry; this research investigates to what degree students from each educational environment mirror this sensibility in the assessment of their own abilities, learning preferences, and educational experiences. Data is based on a series of fifty (50) one-on-one interviews with students, 22 of whom come from a coding bootcamp background and 28 who come from a four-year college. Alongside these interviews, students completed both pre-surveys (50 students) and post-surveys (19 students) on learning preferences and programmatic experience; 12 students also participated in followup interviews further articulating their learning experiences. Results indicate that despite significant differences in age and workforce experience, coding bootcamp students and undergraduates differ little in how they perceive themselves as learners. However, there were notable differences in reasons for application to respective programs as well as exposure to practical learning experiences through coursework. Discussion focuses on the degree to which the aforementioned "soft skills" are perceived as learned expertise versus personal attributes, and to what degree such perception may contribute to higher education's pedagogical and curricular approaches to CS instruction.
\end{abstract}

\section{CCS CONCEPTS}

User characteristics; collaborative and social computing; education

\section{KEYWORDS}

Coding bootcamp; experiential learning; soft skills; learning environment; learning preferences

Permission to make digital or hard copies of all or part of this work for personal or classroom use is granted without fee provided that copies are not made or distributed for profit or commercial advantage and that copies bear this notice and the full citation on the first page. Copyrights for components of this work owned by others than ACM must be honored. Abstracting with credit is permitted. To copy otherwise, or republish, to post on servers or to redistribute to lists, requires prior specific permission and/or a fee. Request permissions from Permissions@acm.org. SIGCSE '19, February 27-March 2, 2019, Minneapolis, MN, USA (c) 2019 Association for Computing Machinery.

ACM ISBN 978-1-4503-5890-3/19/02...\$15.00

https://doi.org/10.1145/3287324.3287373

\section{ACM Reference format:}

Quinn Burke and Cinamon Sunrise Bailey. 2019. Camp or College? Student Perspectives from College Computer Science Departments and Coding Bootcamps on Skills Learned. In Proceedings of ACM Special Interest Group on Computer Science Education (SIGCSE'19) Feb. 27-March 2, 2019, Minneapolis, MN, USA. ACM, New York, NY, USA, 6 pages. https://doi.org/10.1145/1234567890

\section{INTRODUCTION}

The Bureau of Labor Statistics [20] projects the U.S. will have over one-million unfulfilled software engineering jobs by 2020, with Code.org [7] listing the current openings in the U.S. at over 600,000 . While post-secondary computer science (CS) enrollments have steadily risen since 2006 [8], the software development industry indicates that college

graduates are lacking necessary skills for entry level positions $[12,18,21]$. What is particularly notable about this skills gap among recent graduates is that industry representatives perceive such a gap in fundamental, broad areas such as problem-solving, peer-to-peer collaboration, and graduates' wider capacity for team leadership. In 2018, LinkedIn [15]-a professional networking website with over 500 million members globally and the 34th most visited site online-conducted an internal investigation of the skills most commonly listed as integral to hiring. Software development skills were widely cited as a "must have" with 472,000 respondents citing these as integral to new hires. Nearly three times as many respondents (1.4 million total), however, indicated that more general communication and collaboration skills were essential of new hires, and pointed out that the demand for these wider "life" skills directly correlated with the increasingly "shorter shelf life" associated with particular technical skills [15].

Into this skills gap steps a new player. Over the past five years, so called "coding bootcamps" have emerged as a new postsecondary education option to help address unfulfilled software engineering jobs. Brief yet intense training programs, coding bootcamps are, on average, 10-12 weeks in duration, and emphasize teaching the programming skills that employers look for from new software developer hires (particularly front-end programming) while also enabling their graduates to grasp the most essential aspects of coding [9]. Such camps are attracting more mature students (Twenty-nine years-old, on average), with more work experience (six years, on average), which industry representatives report as being a unique value-added to their code camp hires [4,9]. Despite their prodigious growth over the past five years, coding bootcamps remain under-investigated in terms of the educational environments they foster; most information the U.S. public has about such camps is largely through popular press, with snippets on what they financially offer to unemployed and 
underemployed individuals and how the software development industry has likewise benefitted [11,16]. There is, in fact, little information about what their students actually think of the programs in terms of curricula and pedagogy. Nor is there much understanding as to how these programs compare to four-year CS degree programs or to what extent each training environment fosters the development of real world problem-solving and collaboration skills.

Funded by a National Science Foundation Core Research and Development Grant, our exploratory research intends to further examine the role of coding bootcamps in post-secondary STEM education. Over the initial stages of the research, we focused on the software industry's perspective of coding bootcamps and hiring managers' perceptions of the quality of bootcamp graduates in relation to those from four-year CS undergraduate programs. Our current focus is exploring student perspectives from both coding bootcamps and undergraduate CS programs in order to examine three research questions: (1) Who are these programs attracting? (2) How do these students perceive their respective learning environments and their capacity to help them develop these requisite "soft" skill sets? and (3) What are the programmatic outcomes characteristic of each training ground? Through student perspectives, this paper reports how each training ground promotes learning through collaboration and real-world experience. We also examine how these student perspectives contribute to the wider picture of career and adult education programs nationally.

\section{BACKGROUND}

A growing body of literature on post-secondary computing education $[1,2,5,9]$ points to the very real need for post-secondary institutions to inculcate more than CS knowledge and coding skills among their graduates for successful entry into software development jobs. "Soft" skills, such as teamwork and clear communication, are likewise essential, and programs are increasingly revisiting where these skills can be explicitly addressed within their respective curricula. Striking a balance between "hard" and "soft" skills has long been a challenge for hiring managers from a range of industries [14-15], though software companies report to especially struggle with hiring able programmers who likewise have the requisite interpersonal and intrapersonal skills for meaningful collaboration as well as "transfer" capacity to bring their knowledge base to new and novel scenarios [8]. The skills that employers report valuing the most include networking, problem solving, leadership, adaptability, and collaboration [6,18], but Janush [13] reports that higher educational institutions do not necessarily provide graduates sufficient educational opportunities to foster these skills.

In 2018, initial research examined the software development industry's perspective of coding bootcamps and how they compared with traditional four-year CS programs [3-4]. Through a series of hour-long focus groups and interviews with hiring managers, "soft" skills, such as critical thinking, teamwork, and collaboration, were altogether twice as likely to come up than "hard" skills among participants [3]. However, this research also found that hiring managers nearly unanimously first sorted applicants based on whether they had obtained a four-year degree or not. The college degree, however, did not necessarily need to be in CS [3-4]. Despite this overwhelming trend of hiring college graduates, industry representatives noted that while a college degree was usually a requisite credential, they often preferred their boot camp hires based on the fact that these hires were usually older and had more experience with hands-on projects and team building [4], reinforcing prior findings [2-3] that the majority of code camp graduates who secured employment postgraduation also had college degrees.

\section{METHODS}

\subsection{Participants}

For this study, we recruited a total of fifty (50) students from four (4) different four-year college CS programs, as well as from a total of three coding boot camps. All programs were located in medium-sized (130K-150K population) southeastern U.S. cities. Table 1 offers a more detailed breakdown of participant geography, race/ethnicity, and gender.

TABLE 1: Participant/ institutional profile

\begin{tabular}{|c|c|c|c|}
\hline Program & $\begin{array}{l}\text { Participants/ } \\
\text { Gender }\end{array}$ & Ethnicity/Race & $\begin{array}{l}\text { Organization } \\
\text { \#/ Profile }\end{array}$ \\
\hline $\begin{array}{l}\text { Coding } \\
\text { Boot Camp }\end{array}$ & $\begin{array}{l}22 \\
(9 \text { females, } 13 \\
\text { males })\end{array}$ & $\begin{array}{l}14 \text { White/ } \\
\text { Caucasian } \\
3 \text { Black/African } \\
\text { American / } \\
\text { African } \\
2 \text { Asian/ South } \\
\text { Asian } \\
1 \text { Latinx } \\
2 \text { Unknown }\end{array}$ & $\begin{array}{l}3 \text { Bootcamps } \\
\text { ( } 2 \text { mid- } \\
\text { sized cities } \\
\text { in GA and } \\
\text { SC) }\end{array}$ \\
\hline $\begin{array}{l}\text { College / } \\
\text { University }\end{array}$ & $\begin{array}{l}28 \\
(12 \text { females, } 16 \\
\text { males })\end{array}$ & $\begin{array}{ll}16 & \text { White/ } \\
\text { Caucasian } \\
4 & \text { Black/African } \\
\text { American / } \\
\text { African } \\
3 \text { Asian/ South } \\
\text { Asian } \\
1 \text { Latinx } \\
1 \text { Kurdish } \\
3 \text { Unknown }\end{array}$ & $\begin{array}{l}4 \text { Universities } \\
\text { (2 mid- } \\
\text { sized cities } \\
\text { in SC) }\end{array}$ \\
\hline
\end{tabular}

Students were recruited through direct visits to bootcamp and college classrooms, as well as through flyers delivered to instructors. Some of the bootcamp students were recruited through "cold" email messages posted via the LinkedIn website.

\subsection{Data Collection \& Analysis}

From April 2017 through February 2018, the researchers conducted fifty (50) one-on-one interviews with participating students. Questions focused on (1) admission processes (2) skills and knowledge obtained in each training ground, and (3) teaching methods and the learning environments characteristic of each training ground. Prior to the interviews, students were asked to complete a pre-survey focusing on how they perceived themselves as learners (Were they open to new ideas/perspectives? Did they try multiple solutions when tackling a problem? Did they prefer to stick with a known solution as opposed to exploring other options?). All focus groups and interviews were subsequently transcribed and qualitatively analyzed using NVivo software first, 
followed by Dedoose software, which supported the overall organization of the findings and the qualitative analysis of data.

Reliability was calculated based on three sample coding comparisons between two coders. Across these three, there was $100 \%$ agreement on the 4 primary codes, $94 \%$ agreement on the secondary codes, and $87 \%$ agreement on the tertiary codes. In order to establish 'descriptive validity', the open-ended interviews were transcribed verbatim, which lead to a more accurate reflection of what the participant had said; and the reporting of the data reflected the same accuracy in that it was coded into themes and portrayed the unfolding of the 'event' in an accurate manner [17]. 'Interpretive validity' was promoted through the reporting of direct answers and the establishment of intercoder reliability methods aimed at capturing data representing the participants' meaning of events as opposed to interpretations based on the researchers' perspectives [17].

In May 2018, a post-survey was sent out to all student participants. Questions focused on job status, workplace environment, and students' perceptions of workplace preparation. A smaller sample of the original participants responded (twelve code camp students and seven college/ university students). Twelve of these students also participated in a follow-up interview to further examine their survey responses.

\section{RESULTS}

The results reported here correspond to our three respective research questions around entering student profile, programmatic learning environment, and student outcomes.

\subsection{Profile of entering students}

Bootcamp students ranged in age from early $20 \mathrm{~s}$ to $\mathrm{mid}$ 50s. Two students had a military background (though neither was funded through the GI bill). Four students had diversity scholarships or funding through the bootcamp. Nineteen bootcamp students (86.5\%) decided to pursue this educational route in order to change careers, advance within their own company, or update their skill set to include computing and/ or software development; and six students (27\%) indicated they chose bootcamp training because they wanted hands-on instruction and/or practical real-world experience. In terms of prior technological knowledge and/or experience prior to admission, twenty bootcamp students $(91 \%)$ stated that they had some form of training or experience in database management, website development, back end and/ or front end programming, full stack development, software development, game creation, CS theory, and/or computer programming languages. Interestingly, six of these students (27\%) indicated that they had some form of university or community college education in CS or website design; and ten students (45\%) stated they were self-taught through free online courses via YouTube, free-Code-Camp, and Codecademy.

As Graph 1 indicates, $82 \%$ already had a bachelor's degree or higher (degrees included business, CS, education, engineering, finance, liberal arts, mass communications, music theory, and the sciences).

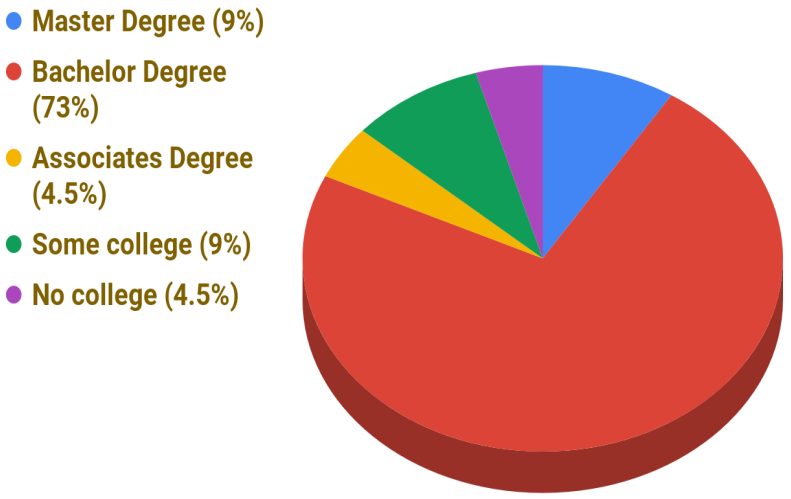

Graph 1: Post-Secondary Education of Boot Camp Students

Pre-surveys revealed that fifteen bootcamp students (68\%) in this study believed that they are open to multiple perspectives when finding solutions and considered themselves multimodal learners, who are flexible about how they give and receive information. Thirteen students (59\%) self-reported metacognition in that they monitor and are aware of their own learning techniques and processes. Interestingly, during their initial interviews, $68 \%$ described themselves as people who "like to learn", "enjoy building things from scratch", "like to problemsolve", and/or "want to challenge themselves".

The interviews with the university students (mean age approximately 22-years-old) revealed, perhaps unsurprisingly, that they had considerably less work experience prior to admission. The geographic origins of the students were broader and included GA, NC, MN, NJ, SC, and WA. Five of these participants were international students from Italy, the Philippines, Morocco, Ethiopia, and Canada, respectively. Fourteen of these participants (50\%) entered as undecided without a CS major in mind. It is interesting to note that $100 \%$ of these undecided students stated that they were initially leaning towards degrees in math, science, and/or engineering. Of all undergraduates, only ten (36\%) had prior work or internship experience.

Nineteen university students $(68 \%)$ reported that they were exposed to CS related courses/assignments while in high school, had self-taught themselves via free computer programming online courses, and/or were taught about software and hardware development by tech adjacent family members and friends during high school. Seven of these participants $(25 \%)$ chose this training ground due to financial aid or scholarships, and four students (14\%) stated that they chose this route because of the importance industry places on having a bachelor's degree or higher.

Pre-surveys revealed that, like the bootcamp students, $68 \%$ of the university students in this study felt that they are open to multiple perspectives when finding solutions and considered themselves multimodal learners, who are flexible about how they give and receive information. 64\% (as compared to 59\% of bootcamp students) demonstrated metacognition in their survey responses in that they monitor and are aware of their own learning techniques and processes.

These results support Course Report's [9] national profile of bootcamp students being significantly older than four-year CS undergraduates, and with more work experience. This is, of course, not surprising; more notable is the fact that our findings 
suggest bootcamp applicants have more digital technological experience prior to programmatic entry, and such students were already highly-educated ( $82 \%$ of bootcamp applicants already had a bachelor's degree or higher). It also suggests that bootcamps, as opposed to graduate schools, are being utilized as an alternative continuing education resource for college graduates who wish to pivot towards a career in the software development field.

\subsection{Student perceptions of learning environment}

Interview responses showed that bootcamp students were notably focused on finding a job or obtaining a promotion immediately after (or even before) completion of their training. Many students' interviews reflected that they felt the coding camp was providing them with a foundation for learning computer programming languages, which would allow them to subsequently grasp other languages more fluidly. For example, a male student with a B.S. in neuro-behavioral biology and a B.A. in Economics, reported that bootcamps are able to help job candidates more immediately show potential employers that they "have the base, [they] have the foundation to analyze and to think about how to approach something." Some students noted their classmates included software development professionals, who came to the code camp in order to update their skill sets.

In regards to the learning environment, over $86 \%$ of bootcamp students reported that hands-on projects and peer collaboration were emphasized and were implemented immediately, and $77 \%$ mentioned that their boot camps work closely with industry with regards to collaboration on student projects and attending demo days to view student projects. Furthermore, several noted that the bootcamp environment was fast paced, encouraged innovation, and emphasized immediate feedback, mimicking their experiences in workplace environments, whether such employment was in software development or not.

Five code camp students (23\%) found the coursework difficult, and three of these students had a CS foundation and/or technical training in the past. For example, one female student, who obtained a CS degree 20 years prior, stated that she "wish[ed] that they had a prep class, something a little bit more for beginners," and added that her instructor "doesn't realize he can't bring it down to [her] level like he should." This is interesting as it indicates that the CS foundations and technical skills, which were taught in her university 20 years ago, were not helpful for employment in today's software development industry. Several bootcamp students reported the fast-paced experience proved difficult due to work and family obligations. A male graduate (age range 41-50), who earned a B.S. in business and remained in the same finance job even after his bootcamp graduation, mentioned that he struggled with the coursework due to his "obligations and responsibilities outside of the camp...there wasn't enough time to process everything and then finish the homework."

Meanwhile, unlike the bootcamp students we interviewed, many of the university students did not have their career plans decided yet. Several, though, seemed optimistic about the job possibilities associated with CS. For instance, a 21-year-old male student, who started off in astrophysics prior to switching to CS, stated "anything I learn could be applied just about anywhere in computer science." Several students reported that their CS courses were providing them with a foundation of how to learn and/or problem solve.
Twenty-four college/university students (86\%) agreed that they were required to take their introductory classes prior to working on more advanced projects in their junior and senior years, and only six students $(21 \%)$ reported working on collaborative projects with industry (versus the $77 \%$ in bootcamps). Notably, four of these six students indicated they had sought out the internship on their own volition. Two university students were either enrolled in or in the process of enrolling in a coding bootcamp in order to get hands-on experience and foundational skills while they also attended their university classes.

According to interviews, a majority of the college students felt they had developed communication skills through group projects and collaboration with peers. Fourteen students $(50 \%)$ indicated that their coursework outside of CS and/or campus organizations likewise helped them develop soft skills, such as teamwork, leadership, ability to communicate effectively, entrepreneurship, risk taking, critical thinking, and cultural awareness. The interviews revealed that there were mixed feelings amongst the students about whether or not the universities encouraged innovation and creativity. A male student, a CS and Math major, stated "I think some of it's particular to the professor. I've had some professors who in some of the classes really want it done the way that they've taught you to do it, and in other classes they're much more open to that innovation or that digging deeper to find something else."

Students from all four college programs reported receiving consistent feedback via grades, though some indicated more supplementary feedback would have been useful. For example, one male student stated "(Y)ou'll turn in some assignments and then you won't hear back for weeks about it, but [you] have to turn in your next assignment...I don't know how to improve, because I haven't gotten feedback yet." A former semiprofessional hockey player, indicated that having different feedback from different professors may prove to be helpful toward future careers: "I think it gives you the flexibility and the dexterity you need depending on what kind of boss you have."

These results suggest that bootcamps provide more immediate emphasis on feedback, industry collaboration, job acquisition, and practical, hands-on experience than do four-year undergraduate programs. This is not to indicate that college CS programs are devoid of such content, but rather that their students reported it occurring later within their individual programs, usually during late junior and senior year of college. Bootcamp students reported on largely appreciating the fast-paced and immersive nature of their respective programs; however, what is less clear from their responses is the degree to which such structure and curricula inculcated their problem-solving and collaboration skills versus simply sharpened these as existing skills.

\subsection{Programmatic Outcomes}

A total of 12 bootcamp students from two different southeastern U.S. cities completed the follow up survey, and had graduated. Of these, seven had obtained a new job in the software industry (fullstack, web design, graphic design, software engineer, data entry, software quality analyst, and technical program manager); and two of these students received help from their instructor/ bootcamp in getting their jobs (both from the same camp). All worked within 20-40 miles from their training ground.

Of the students, who had not yet found new employment, two were still looking for a position; and three graduates reported being in the same position that they were in before code camp 
training and were hoping for a promotion and/or increased programming opportunities (network support manager, marketing, and UX design).

During their first and second interviews, several of the bootcamp students indicated that the ability to learn quickly was important in the workplace, and that they had to demonstrate this in their interviews. Six participants attributed their ability to get a job with their boot camp training and/or connections. For one bootcamp graduate, a male with a BS in Science and Psychology, having bootcamp training was both a positive and a negative attribute. For hiring, he stated, "Going from zero to 60 in three months I think was something I was able to tout as a skill." However, he was hired in a quality assurance position rather than in the engineering department he wanted "because they had had so many bad experiences that none of the managers, were actually willing to take on another boot camp grad." The student with only a high school education stated that "(h)aving only a highschool diploma and the coding school certificate doesn't really make [him] a very competitive worker, at least not on paper."

With regards to soft skills, first and second interviews revealed that thirteen of these participants indicated they had entered their bootcamp training with their soft skills already embedded through their college experience, work experience, and/or their own desire to continue learning and/or to problem-solve. For example, a female, with a master degree in music education, associated her soft skill development with her musical and teaching background, which had occurred years before entry into the camp. All thirteen of these students expressed that although they had come into their respective bootcamp programs with their soft skills intact, the bootcamp environment nonetheless emphasized the importance of such skills as particular levers they should use to their advantage as they prepared for software development careers. "[T]hey didn't necessarily train us in soft skills," explained one code camp graduate who likewise had a college degree. "They just provided the environment for us to learn those soft skills on our own in a non-corporate environment." On the other hand, five students $(23 \%)$ indicated that the bootcamp setting very much helped them develop soft skills, such as collaboration, effective problem-solving, time management, determination, and accountability. For example, a female code camp graduate, who had already earned a master's degree, directly credits her job promotion and some of her soft skill development to her code camp experience. "(A)fter the class," she explained, "I feel more comfortable experimenting, trying, teaching myself." The sole international bootcamp student in our study seconded this sentiment, indicating that while he had such soft skills prior to admission, his bootcamp allowed him to learn "American soft skills" and more ably grasp U.S. customs, such as "being able to be friendly with your boss".

Within the post-survey, seven university students from two different southeastern U.S. cities responded. Of these students, two had graduated and acquired a job (data center infrastructure monitoring and software engineer). These jobs were located within 30-40 miles of their university. Two students were in internships with software development companies, while also attending classes; the remaining three were still solely focusing on coursework at the time of the survey.

In the second set of interviews, all three CS graduates indicated that they were able to learn "how to learn" in college. One stated that the university "gave [him] a very good framework even when presented with terms that [he] didn't have any experience with." Another added "I think that I have a very developed critical thinking ability from a university style education." An Italian international student, despite being pleased with his semester in a southeastern U.S university, indicated that "what was lacking in university was ... it was all very, let's say, 'theoretical'. We learned out of a textbook.... We don't really learn how to really directly implement it in the business setting."

These results indicate that bootcamp students more often perceive themselves as already personally and socially developed-perhaps unsurprising given their greater maturity and levels of experience. As noted earlier though, it is difficult to determine if these were innate skills or hard-earned through past work and prior educational pursuits. Students from both training grounds recognized that their programs were attempting to instill and/or reinforce soft skills, such as collaboration and problemsolving.

\section{DISCUSSION}

In Soft Skills for Business Success, Deloitte Access Economics [10] predicts that by 2030, company positions that are "soft skills intensive" can be expected to grow at more than double the rate of other types of positions. This trend is evident in the software industry's increased ownership of such skills development, with companies increasingly offering seminars and classes in-house to inculcate such soft skills among employees, especially for new hires $[1,3-5$,$] . This is not however to imply that these same$ companies are happy about having to take ownership over such coursework [18], and many of these companies report of being all too aware that the majority of CS undergraduate programs are still not explicitly addressing the development of these crucial interpersonal and intrapersonal skills $[6,15,18]$. It is worthy to point out that $50 \%$ of the college and university students in this study indicated that they were developing soft skills like teamwork, collaboration, leadership, and problem solving through their respective CS programs and through their general education courses, electives, and campus organizations. But these undergraduates were not necessarily able to project why or how they would utilize these skills in the workplace. Meanwhile, 59\% of bootcamp students emphasized that they had entered their respective programs already endowed with these soft skills based on prior educational and work experiences. These students provided specific examples of how they have demonstrated leadership, teamwork, and problem-solving within their career and why it was important that they utilized these particular skills in the workplace.

Still, it is altogether difficult to ascertain as to where and when the university and bootcamp students developed their reported soft skills, and whether such development occurred at stages far more nascent than post-secondary education. Here it is worthwhile to return to the existing literature $[1,5,19]$, which suggests that post-secondary graduates' lack of such requisite interpersonal and intrapersonal skills often directly stems back to the wider (and persistent) conception among post-secondary college and university educators that these elements are not learned skills but rather personal attributes that individuals either have or do not have upon programmatic entry, and thus by extension, cannot be taught. This perception, to a degree, then can tacitly absolve said instructors and post-secondary programs from having to explicitly teach such content to their students. Bootcamp student perspectives meanwhile suggest that these programs are explicitly engaging in practices, which promote the soft skills that employers are seeking from new hires (i.e. 
increased critical feedback to prepare students for giving and receiving feedback in the workplace, real world practice from week one in programs, and increased opportunities to be exposed to the industry). This perspective from code camp students is supported by our past research examining industry perspectives on such camps [3].

\section{Limitations \& Future Research}

Of course, the conclusions presented here--though bolstered by a range of metrics and non-student perspectives--rely heavily on self-reporting from student participants. This and the modest sample size present significant limitations to this still exploratory research. Though there were fifty (50) student interviews coupled with surveys, this represents a relatively small number and was limited to the southeastern region of the U.S. Despite the limitations, the research presented here has significant educational implications for post-secondary computing education. By providing a learning environment that includes greater immersion into real world applications, increased industry collaborations, and more immediate critical feedback, colleges could contribute even more to closing the "soft skills gap" and more ably prepare students for entering and performing in the rapidly changing workplace characteristic of software development.

While the research here presents student perspectives and past research [3] presented industry perspectives, going forward, we will examine individual instructor perspectives from each learning environment: How do they perceive these soft skills and to what degree do they teach (and think they can, in fact, teach) such skills to post-secondary students?

In addition to examining instructors' perceptions, we will explore instructional practices with regards to how soft skills are incorporated into the curriculum, examining select syllabi and assignments across camp and college/ university classroom. Including further analysis of instructional perspectives will likewise act as an important supplement to the existing perspectives we have examined from industry reps and students.

\section{ACKNOWLEDGMENTS}

The writing of this paper was supported through a National Science Foundation (NSF) Core Research and Development Grant to the first author. The views expressed are solely those of the authors.

\section{REFERENCES}

[1] Ahmed, F., Capretz, L.F., Bouktif, S., \& Campbell, P. 2013. Soft skills and software development: A reflection from software industry. International fournal of Information Processing and Management, 4(3).

Doi:10.4156/ijipm.vol4.issue3.17

[2] Burke, Q., Bailey, C., Lyon, L.A., \& Bowring, J. (2017, August 29). "Earning a college degree in order to go to camp?" Inside Higher Education. Available at https://www. insidehighered.com/views/2017/08/29/essay-how-coding-bootcamps-are-add-college-degree.

[3] Burke, Q., Bailey, C.. 'Lyon, L., \& Green, E. 2018. Understanding the software development industry's perspective on coding boot camps versus traditional 4-year Colleges. Proceedings from AERA '18. The Dreams, Possibilities, and Necessities of Public Education, April 13-17, 2018 New York, $N Y, U S A$
[4] Authors. 2018. Assessing industry's perspective of coding boot camps through the Lens of routine and adaptive expertise. Proceedings from SIGCSE '18: The 49th ACM Technical Symposium on Computer Science Education, February 21 - 24, 2018, Baltimore, Maryland, USA

[5] Capretz L.F. and Ahmed, F. 2010. Why do we need Personality diversity in software engineering. $A C M$ SIGSOFT Software Engineering Notes, 35(2). doi: 10.1145/1734103.1734111.

[6] Casner-Lotto, J. \& Barrington, L. 2006. Are they really ready to work? Employers' perspectives on the basic knowledge and applied Skills of new entrants to the 21st Century U.S. workforce. Partnership for 21s Century Skills. Washington, DC: Partnership for 21st Century Skills.

[7] Code.org. 2017. Computer science education stats. Retrieved from: https://code.org/promote

[8] Computing Research Association. 2017. Generation CS: Computer science undergraduate enrollments surge since 2006. Available at http://cra.org/data/Generation-CS/

[9] Course Report. 2017. Retrieved from: https://www.coursereport.com

[10] Deloitte Access Economics. 2017. Soft skills for business success. Retrieved from: https://www2.deloitte.com/

[11] Greenman, M. 2016. Intensive training helps coding newcomers land technology jobs. (September 2016). Available at: http://425business.com/intensivetraining-helps-coders-land-technology-jobs/

[12] Indeed. 2017. What do employers really think about coding boot camps? Available at: http;//blog.indeed.com/2017/05/ 02/what-employers-really -think-about-coding-bootcamp/

[13] Janush, S. 2017. Bringing soft skills to the forefront: How higher ed (and continuing ed) must adapt

[14] Lapowsky, I. (2016, August 16). Can't afford a coding bootcamp? Available at https://www.wired.com/ 2016/08/white-house-rolls-student-loans-coding-camps/

[15] LinkedIn Learning. 2018. 2018 Workplace learning report: The rise and responsibility of talent development in the new labor market. Retrieved from: https://learning.linkedin.com/content/dam/me/learning/ en-us/pdfs/linkedin-learning-workplace-learningreport-2018.pdf

[16] Lohr, S. (2017). A new kind of tech job emphasizes skills, not a college degree. The New York Times. Available at https://www.newyorktimes.com/2017/06/28/technology/techSkills-college-degree, html?mcubz=2 Doi: http://dx.doi.org/10.18260/p.24716

[17] Maxwell, J. A., 1992, Understanding and validity in qualitative research. In A. M. Huberman \& M. B. Miles (Eds.), The Qualitative Researcher's Companion, (pp. 37-64). Thousands Oaks, CA: Sage Publications.

[18] Mourshed, M., Farrell, D., \& Barton, D. 2013. Education to employment. National Partnership for Educational Access: Research Brief. Available at https://npeac memberclicks.net /assets/education\%20to\%20employment.final.pdf

[19] Pritchard, J. 2013. The importance of soft skills in entry-level employment and post-secondary success: Perspectives from employers and community colleges. Available at http://www.seattlejobsinitiative.com/wpcontent/uploads/SJI_SoftSkillsReport_vFINAL_1.17.13.pdf

[20] The U.S. Bureau of Labor Statistics. 2017. Available at https://www.bls.gov.

[21] Van Velsor, E.V. and Wright, J. 2012. Expanding the Leadership Equation Developing Next-Generation Leaders. Center for Creative Leadership. Available at https://ccl.org/wp-content/uploads/2015/04/Expanding LeadershipEquation.pdf 